\title{
REALISMO E INDETERMINACIÓN (APROXIMACIÓN TEÓRICO-CRIITICA). EL CASO DE LA REGENTA DE LEOPOLDO ALAS, "CLARÍN"1
}

\author{
REALISM AND INDETERMINATION (A THEORETICAL- \\ CRITICAL APPROXIMATION). THE CASE OF LA REGENTA \\ BY LEOPOLDO ALAS, "CLARÍN"
}

\section{EDSON FAÚNDEZ V. ${ }^{2}$}

\section{RESUMEN}

Este artículo estudia dos problemas de La Regenta de Leopoldo Alas “Clarín": la producción de la ilusión de realidad y la presencia de la indeterminación en las dimensiones estructural y dialógica.

Palabras clave: Literatura española, mimesis, estructura, dialogismo.

\section{ABSTRACT}

This article studies two problems in La Regenta by Leopoldo Alas "Clarin": the production of the illusion of reality and the presence of indetermination in the structural and dialogical dimensions.

Keywords: Spanish literature, mimesis, structure, dialogism.

Recibido: 13.07.11. Aceptado: 10.02.12.

${ }^{1}$ Artículo escrito dentro del marco del Proyecto FONDECYT de Iniciación en Investigación No 11075025, titulado "Mímesis y deseo en la novela realista decimonónica: La Regenta de Leopoldo Alas, 'Clarín'”.

${ }^{2}$ Dr. en Literatura Latinoamericana. Profesor del Depto. de Español Universidad de Concepción. Concepción, Chile. E-mail: efaundez@udec.cl 


\section{SOBRE LA ILUSIÓN DE TRANSPARENCIA}

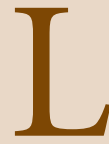

A AMBIGÜEDAD Y POLISEMIA del término realismo, el cual puede aludir a una escuela o período literario, a una constante de toda la literatura y de las artes o a un problema que exige una reflexión teórica, dificultan la singularización de los signos distintivos del realismo literario. Consideraciones de tipo filosófico, estético y lingüístico ${ }^{3}$, además, se conjugan al momento de precisar los principios teóricos y metodológicos que guían el estudio del corpus textual realista decimonónico.

Las teorías sobre el realismo literario, que dominan durante el siglo XIX y gran parte del siglo XX, proponen que el texto literario constituye un reproductor fiel de la realidad externa o una instancia discursiva autónoma, en la que la realidad se produce a través del lenguaje ${ }^{4}$. El realismo genético o mimético, que encuentra en las proposiciones del naturalismo de Emile Zola sus claves fundamentales, se funda por ello en una correspondencia transparente entre el mundo externo y el texto literario. Esta equivalencia "natural" entre el signo lingüístico y el referente sugiere que el naturalismo se origina "en la realidad y, a la vez, en la captación objetiva de la misma por parte del escritor" (Villanueva, 2004: 51). El realismo inmanente o formal, que surge a partir de las reflexiones del autor de Madame Bovary, plantea, por otra parte, que la realidad es construida por el lenguaje literario. La realidad deviene, desde esta perspectiva, en una ilusión a la que se arriba mediante un estilo que persigue, entre otros aspectos, la invisibilidad de la forma y la visibilidad del mundo narrado ${ }^{5}$. Las teorías mimética y formal, empero, no abordan las complejidades inherentes a las relaciones que se establecen entre el texto y lo extratextual. Una posibilidad de acceso al es-

\footnotetext{
${ }^{3}$ Estas consideraciones, según Darío Villanueva (2004), inciden, por ejemplo, en la percepción de la realidad, las relaciones entre el arte y la filosofía, el signo y el referente.

${ }^{4}$ Sigo las proposiciones, en este punto, de Darío Villanueva (2004).

${ }^{5}$ En palabras de Darío Villanueva: "El realismo inmanente y formal del que hablamos resulta, pues, de una construcción, y no de la trasposición cristalina de una alteridad que le sería preexistente" (2004: 75). Benito Pérez Galdós, en su "Prólogo" a La Regenta, establece la distancia irreductible entre los mundos de la ficción y de la "realidad" extratextual: "ciertamente, parece que nos ennoblecemos trasladándonos de este mundo al otro, de la realidad en que somos tan malos a la ficción en que valemos más que aquí, y véase por qué, cuando un cristiano tiene el hábito de pasar fácilmente a mejor vida, inventando personas y tejiendo sucesos a imagen de los de por acá, le cuesta no poco trabajo volver a este mundo" (1900: V).
} 
tudio del realismo literario surge al aplicar algunas nociones provenientes de las teorías del efecto estético y de la recepción formalizadas en la Escuela de Constanza hacia finales de la década del 60. Esto permite superar, como sugiere Darío Villanueva (2004), la desconexión entre la novela y la realidad exterior, entre la literatura y la vida, en la que desembocan la crítica genética y la crítica inmanente.

La ilusión realista es resultado de la interacción entre la estructura del texto literario y sus potenciales lectores. Todo texto literario existe, por lo tanto, en un plano de virtualidad, ya que sólo logra convertirse en obra estética a partir del acto de lectura. Uno de los signos distintivos del texto literario, según Roman Ingarden, es su condición de realidad lingüística inacabada, es decir, el texto exige una complementación cooperativa intensa e inagotable de parte del lector ${ }^{6}$. El acto de lectura cifra así las "nupcias creadoras" por las cuales se liberan los sentidos del texto para ser recibidos y modificados por el lector ${ }^{7}$. La fusión del polo artístico -el texto literarioy el polo estético -realización que hace el lector- permite el surgimiento de una zona en donde texto y lector se encuentran ${ }^{8}$. Es, en suma, mediante la recepción estética que la ficción literaria y el mundo del lector, la literatura y la vida, interactúan productivamente, permitiendo la irrupción de los siempre mutables rostros de la obra. Las innumerables incursiones a La Regenta, que leen la novela de Alas como un plagio de Madame Bovary

\footnotetext{
${ }^{6}$ Roman Ingarden escribe: "la obra literaria, en cuanto tal, es una formación puramente intencional que tiene la fuente de su ser en actos de conciencia creativos de su autor, y cuyo fundamento físico está en el texto escrito o en otro medio físico de posible reproducción (como por ejemplo una cinta magnética). En virtud del estrato dual de su lenguaje, la obra es accesible intersubjetivamente y reproducible, de manera que se convierte en un objeto intencional intersubjetivo, relativo a una comunidad de lectores. De este modo no es un fenómeno psicológico, sino que trasciende todas las experiencias de conciencia, tanto del autor como del lector" (1989: 36).

${ }^{7}$ Tomo la noción de "nupcias creadoras" del pensamiento filosófico de Gilles Deleuze y Félix Guattari (1990).

${ }^{8}$ Wolfgang Iser, en "La interacción texto-lector: algunos ejemplos hispánicos", escribe: "La obra literaria tiene dos polos que pueden denominarse el polo artístico y el polo estético: el polo artístico es el texto del autor, y el estético es la realización que hace el lector. En vista de esta polaridad, se hace manifiesto que la obra misma no puede ser idéntica al texto ni tampoco a su actualización sino que debe ser situada entre esos dos extremos. Inevitablemente tendrá que tener un carácter virtual en cuanto no se la puede reducir a la realidad del texto ni a la subjetividad del lector, es a partir de esta virtualidad que se deriva su dinamismo. Según el lector atraviesa las diversas perspectivas que el lector ofrece y relaciona los distintos enfoques y estructuras entre sí, pone la obra en movimiento al mismo tiempo que se pone a sí mismo en movimiento también". (1982: 225). Félix Vodička, por su parte, en "La estética de la recepción de las obras literarias", señala: "sólo cuando una obra es leída llega a su realización estética, sólo así se convierte en la conciencia del lector en objeto estético" (1989: 55).
} 
(Bonafoux, 1894) o la rescatan como una de las obras maestras de la literatura universal (revista Archivum 1954 y escritores de los años 50 a 60) ${ }^{9}$, no impiden por ello que la novela escrita entre 1884 y 1885 continúe siendo hoy día, en la época en que ningún acontecimiento pareciera ser ya posible, un acontecimiento estético y ético de máxima importancia ${ }^{10}$.

El realismo literario, en efecto, "es un fenómeno fundamentalmente pragmático, que resulta de la proyección de una visión del mundo externo que el lector -cada lector- aporta sobre un mundo intencional que el texto sugiere" (Villanueva, 2004: 126). La novela, a partir de una serie de estrategias textuales -verdaderas instrucciones e indicaciones del texto-, organiza la pre-visión del tema y también sus condiciones de comunicación. Philipe Hamon (1973) señala, por lo mismo, que la escritura realista es un discurso forzado, puesto que reconoce en las estrategias textuales el peso de los mecanismos de control interno del texto que inducen respuestas preorientadas en el lector (Hamon, 1973). Las técnicas composicionales recurrentes, que tienen por finalidad la producción "de una visión imaginaria de la experiencia humana” (Martínez Bonati, 39), afectan al lector para

${ }^{9}$ Gonzalo Sobejano, en Clarín en su obra ejemplar, escribe: "la recuperación de Clarín, que se inicia con el centenario y se cumple en gran parte en los años 60 , no fue una moda, como piensa Valverde: fue un acto de justicia, y por cierto ha tardado mucho en alcanzar un grado satisfactorio. Mucho hubo de contribuir a la recuperación de Alas, la de Galdós, iniciada antes y fuera de España, a raíz, cómo no, del centenario de su nacimiento (fundamental fue el libro tantas veces reeditado de Joaquín Casalduero). Pero, además, la novela social de los años 50 a 60, algo había de favorecer a los dos grandes maestros del realismo más o menos naturalista y, en todo caso, crítico: y Santos Sanz Villanueva ha recordado opiniones muy favorables a Clarín de J. A. Goytisolo (1961) y de su hermano Luis (1959); no menos declarada es la admiración de Juan Goytisolo hacia el crítico Clarín y hacia su mayor novela La Regenta, bien conocida por Juan Benet” (1991: 182).

${ }^{10}$ La Regenta ha sido leída como una novela que plagia a Madame Bovary (Bonafoux 1894) o como una novela fuertemente influenciada por la novela de Flaubert (Pardo Bazán 1911). (Ruiz de Gordejuela 1952). También La Regenta ha sido leída como una novela cuyo motivo es el adulterio (Naupert 2001), pero que establece notables diferencias con las serie de novelas de adulterio del siglo XIX (Bobes Naves 2002); como un relato que tematiza el proceso psicológico que lleva a Ana Ozores a "discernir si debe perderse por lo clerical o por lo laico" (Pérez Galdós 1900: XVI); como "un estudio de una concepción romántica de la vida, pero, situada en un marco realista [...] El conflicto entre la subjetividad de la protagonista y el mundo social, actuando éste como impedimento insalvable para la realización de aquélla, se establece como núcleo temático de la obra" (Beser 1982: 69); como fuente de diálogos infinitos: Stephen Gilman, en "La novela como diálogo: La Regenta y Fortunata y Jacinta” (1975), examina el diálogo intertextual entre la novela de "Clarín” y la novela de Benito Pérez Galdós. Gonzalo Sobejano, en Clarín en su obra ejemplar, analiza La Regenta y Su único hijo a la luz de novelas europeas. Robert Fedorchek, en "Clarín y Eça de Queiroz" (1978), estudia los vínculos entre estos dos escritores. G. Laffitte, en "Madame Bovary et La Regenta” (1943), y Carlos Clavería, en "Flaubert y La Regenta de Clarín” (1942), analizan el bovarysmo en la escritura de Leopoldo Alas. Y la lista de trabajos continúa. 
que concretice la narración en clave realista. Itamar Even-Zohar denomina "realemas" a los operadores de realidad (1985) de las formas de expresión y contenido que contribuyen a que el lector perciba el texto como un discurso verosímil, familiar y objetivo ${ }^{11}$. Los realemas más frecuentes y significativos en La Regenta son: el predominio del narrador en tercera persona, la recurrencia de nombres propios, históricos o geográficos -antropónimos y topónimos-, el carácter descriptivo de la narración, la preocupación por el detalle, la legibilidad, la presencia de cuadros de costumbres, la individuación de los personajes, el habla de los personajes dominada por el decoro, la proximidad entre lo enunciado y la enunciación. No todos los realemas que configuran el catálogo del realismo y naturalismo del siglo XIX, sin embargo, funcionan en el caso de La Regenta. La diferencia de la novela de Alas ${ }^{12}$, en este sentido, se expresa en la inclusión de la subjetividad y el lirismo, destacada por Gonzalo Sobejano, quien observa en la prosa de Alas “elevación, pasión de Infinito, intimidad, grandeza de propósito y de acción, fidelidad al sentimiento profundo, emoción, musicalidad, impulso lírico, aversión al prosaísmo de las buenas circunstancias" (1991: 166). La "fidelidad al sentimiento profundo" conduce el estilo de Alas a la transgresión del modelo escritural establecido. Ello se advierte incluso en el título temático de la novela ${ }^{13}$, el cual, como lo ha estudiado John Rutherford (2002), es ambiguo

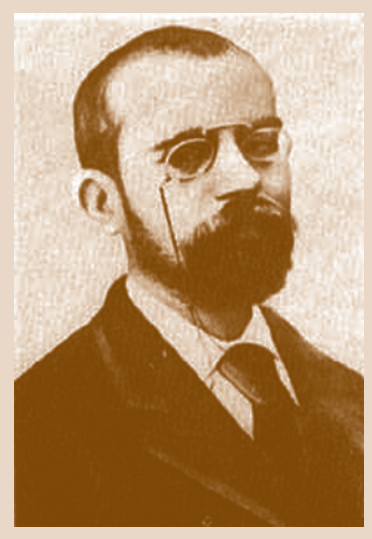

L. Alas, "Clarín"

${ }^{11}$ Félix Martínez Bonati, en El Quijote y la poética de la novela, advierte que "la verosimilitud aristotélica no basta para concretizar lo que modernamente llamamos realismo [...] Verosimilitud, esto es, consistencia con lo tenido por posible, probable y necesario y, además, congruencia con la experiencia ordinaria, o sea la familiaridad de la clase de objetos y acciones representados, son, pues, sino todos, dos de los rasgos fundamentales de la ficción realista [...] No se trata aquí de la clase de personas representadas (heroicos semidioses, hombres como nosotros, criaturas subhumanas), sino de la dirección en que opera la abstracción figurativa que las representa: hacia arriba (dirección que podemos llamar 'idealizante'), hacia abajo ('caricaturizante') o nivelada con la experiencia ('objetiva'). (Luciano, por ejemplo, no pinta a los dioses como Homero). El principio de estilización objetiva es, obviamente, el que corresponde al concepto de realismo." (2004: 34-36).

${ }^{12}$ Luis Galván, en "Notas sobre la recepción de La Regenta: lector implícito y lecturas reales", señala que la recepción naturalista de la novela de Alas se debe fundamentalmente a que la obra "quedó sumida en el horizonte de expectativas dominante, producido por una ruidosa polémica [se refiere al debate sobre el naturalismo en el que participa Alas]" (1999: 410). La tesis de Galván propone que La Regenta supera el naturalismo en la medida en que introduce "largas y señaladas retrospecciones" y despliega una conclusión novelesca "en cierta medida abierta y recurrente" (1999: 408). El relato, por otro lado, puede "responder a una pregunta olvidada por el sistema positivista y la estética naturalista, una pregunta por el papel del sujeto en la elaboración de su propia vida [Galván sigue, en este punto, la lectura de María del Carmen Bobes Naves]” (1999: 410).

${ }^{13}$ Considero que la novela de Alas tiene un título temático, en el sentido propuesto por Gérard Genette en Umbrales: “el adjetivo temático para calificar los títulos que comprenden el 'contenido' del texto no es irreprochable, ya que supone un agrandamiento abusivo de la noción de tema [...] 
y remite a un apodo y no a un nombre como es característico en las novelas del período:
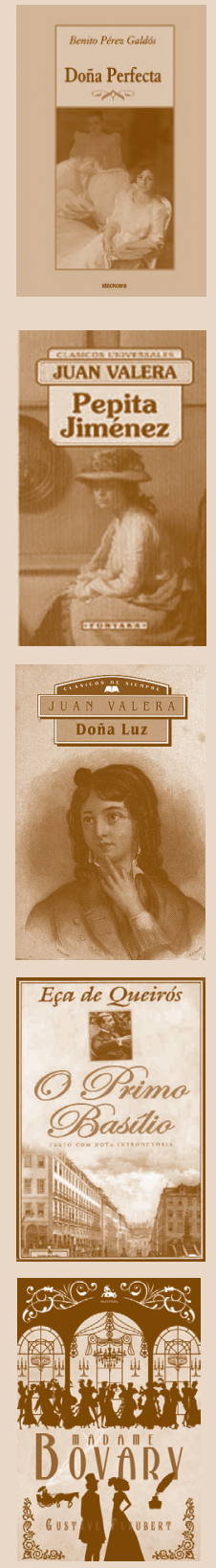

Regenta es una palabra plurivalente, sobre todo cuando aparece casi sola en la cubierta de una novela, desprovista del contexto lingüístico que pudiera haberle quitado su ambigüedad. Será por este necesario aislamiento inicial por lo que los títulos de las grandes novelas decimonónicas suelen ser explicativos y transparentes. Muchas veces consisten en meros nombres: Doña Perfecta, Fortunata y Jacinta, Pepita Jiménez, Doña Luz, Pedro Sánchez, O primo Basilio, Madame Bovary, Ana Karenina, Oliver Twist, David Copperfield. Pero en el caso de la novela de Clarín, en claro y audaz contraste con la tradición establecida, nos encontramos con un título equívoco, ambiguo y enigmático: no un nombre sino (como descubriremos después al ir leyendo el texto) un apodo (2002: 100).

La transparencia de La Regenta no sólo se resiente con el título, sino también con el uso de puntos suspensivos, comillas y letra cursiva. Cualesquiera sea la finalidad estética de estos recursos (incidir en el ritmo, marcar la voz de los personajes, destacar las ironías), lo cierto es que la invisibilidad de la forma, perseguida como verdadero ideal por el naturalismo de Zola, se ve afectada; dicho problema se amplifica con la presencia de la ironía, la parodia y la caricatura, de figuras retóricas como el oxímoron de la primera oración de la novela o de las mismas tensiones singularizadoras de La Regenta-signos todos de la estética grotesca a la que, según Kronik (1987), se adhiere la novela- que inducen al lector a centrar su atención en "el artefacto que es La Regenta y [en] la artesanía que Alas ha invertido en su elaboración" (Kronik, 1987: 520) ${ }^{14}$. El humor constituye otro de los recursos clarinianos que hace evidente lo que según los propios escritores naturalistas debiera permanecer inadvertido para el lector: el artificio literario ${ }^{15}$. El humor clariniano, que "es enormemente rico y abarca toda

un lugar (tardío o no), un objeto (simbólico o no), un leitmotiv, un personaje, incluso central, no son propiamente dichos temas, sino elementos del universo diegético de las obras que titulan. Calificaré no obstante todos estos títulos de temáticos, por una sinécdoque generalizante que será, si queremos, un homenaje a la importancia del tema en el 'contenido' de una obra, sea del orden narrativo, dramático o discursivo. Desde este punto de vista, todo lo que en el 'contenido' no es tema, o uno de los temas, está en relación empírica o simbólica con él y con ellos” (2001: 72-73).

${ }^{14}$ Para profundizar en el estudio de la estética grotesca clariniana, consúltese el artículo de John Kronik "El beso del sapo: configuraciones grotescas en La Regenta” (1987).

${ }^{15}$ Según Luis Galván (1999), las largas retrospecciones y la conclusión novelesca constituyen características que alejan la novela de Alas de la estética naturalista. Véase nota 13. 
una serie de registros: desde el humorismo lírico al puramente cómico, a la ironía sutilísima, al sarcasmo tajante, al esperpento grotesco" (Oleza, 1976: 159), contribuye notablemente a iluminar y censurar los vicios y errores sociales dominantes, a la vez que incita al lector a reflexionar y percibir en su entorno y en sí mismo dichos vicios y errores sociales. El capítulo VII de la primera parte de La Regenta, que muestra la disputa entre Frutos Redondo y Pepe Ronzal acerca de la ortografía de la "palabreja" avena, es clave en este sentido:

-Hombre, a propósito de sabios -dijo don Frutos Redondo, el americano, que hasta entonces no había hablado-. Tengo pendiente una apuesta con usted, señor Ronzal... ya recordará usted... aquella palabreja.

-¿Cuál?

-Avena. Usted decía que se escribe con $h . .$.

-Y me mantengo en lo dicho, y lo hago cuestión personal.

-No, no; a mí no me venga usted con circunloquios; usted había apostado unos callos...

-Van apostados.

-Pues bueno ¡ajajá! Que traigan el Calepino, ese que hay en la biblioteca.

-iQue lo traigan!

Un mozo trajo el diccionario. Estas consultas eran frecuentes.

-Búsquelo usted primero con $h$-dijo Ronzal con voz de trueno a Joaquinito, que había tomado a su cargo, con deleite, la tarea de aplastar al de Pernueces.

Don Frutos se bañaba en agua de rosa. Un millón, de los muchos que tenía, hubiera dado él por una victoria así. Ahora verían quién era más bruto. Guiñaba los ojos a todos, reía satisfecho, frotaba las manos.

- ¿Qué callada! ¡qué callada!

Orgaz, solemnemente, buscó avena con $h$. No pareció.

-Será que la busca usted con $b$; búsquela usted con $v$ de corazón.

-Nada, señor Ronzal, no parece.

-Ahora búsquela usted sin $h$-exclamó don Frutos, ya muy serio, queriendo tomar un continente digno en el momento de la victoria.

Ronzal estaba como un tomate. Miró a Mesía, que fingió estar distraído.

Por fin Trabuco, dispuesto a jugar el todo por el todo, se puso en pie en medio de la sala y cogió bruscamente el diccionario de manos de Orgaz, que creyó que iba a arrojárselo a la cabeza. No; lo lanzó sobre un diván y gritando dijo:

-Señores, sostenga lo que quiera ese libraco, yo aseguro, bajo palabra de honor, que el diccionario que tengo en casa pone avena con $h$.

Don Frutos iba a protestar, pero Ronzal añadió sin darle tiempo:

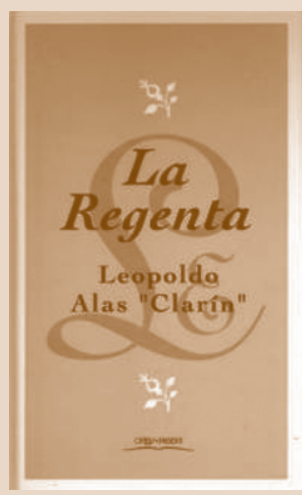


-El que lo niegue me arroja un mentís, duda de mi honor, me tira a la cara un guante, y en tal caso... me tiene a su disposición; ya se sabe cómo se arreglan estas cosas.

Don Frutos abrió la boca.

Foja, desde la puerta, se atrevió a decir:

-Señor Ronzal, no creo que el señor Redondo, ni nadie, se atreva a dudar de su palabra de usted. Si usted tiene un diccionario en que lleva $h$ la avena, con su pan se lo coma; y aun calculo yo qué diccionario será ese... Debe de ser el diccionario de Autoridades...

-Sí señor; es el diccionario del Gobierno...

-Pues ese es el que manda; y usted tiene razón y don Frutos confunde la avena con la Habana, donde hizo su fortuna...

Don Frutos se dio por satisfecho. Había comprendido el chiste de la avena que se había de comer el otro y fingió creerse vencido.

-Señores -dijo- corriente, no se hable más de esto; yo pago la callada. (Alas 1900: 203-205)

La insensata apuesta de unos "callos" revela aspectos de máximo interés. Sabemos que Frutos Redondo es considerado un ignorante por los socios del Casino y que Pepe Ronzal, en el capítulo anterior, ha decidido convertirse en un hombre sabio, guiado sólo por la certidumbre de que "el mundo daba mucho a las apariencias, y que en el Casino pasaban por más sabios los que gritaban más, eran más tercos y leían más periódicos del día" $[\ldots]<<$ esto de la sabiduría es un complemento necesario. Seré sabio. Afortunadamente, tengo energía (tenía muy buenos puños) y a testarudo nadie me gana, y disfruto de un pulmón como un manolito (manolito, por supuesto). Sin más que esto y leer La correspondencia, seré el Hipócrates de la provincia >>" (Alas, 1900, I: 190). El proyecto de Ronzal (nótese que el narrador sobre la base del distanciamiento irónico invita al lector a pensar en el sentido de las relaciones entre sabiduría y energía -poder/violencia- y a valorar negativamente el proyecto del iluso personaje) se pone en práctica en la apuesta con Frutos Redondo. Trabuco "bruscamente" toma el diccionario en el cual Orgaz busca la palabra havena; lanzándolo sobre un diván, lo desautoriza, asegurando que en $s u$ diccionario dicha palabra existe. Defiende el argumento con la energía que lo define y la promesa de violencia implícita en el despliegue de su código de honor. Ronzal muestra, por último, que desconoce la existencia del "diccionario de Autoridades" al confundirlo con un supuesto "diccionario de Gobierno". La silenciosa burla generalizada acompaña el falso triunfo de Trabuco. La escena anterior mueve al lector a risa, a la vez que lo invita a considerar reflexivamente los móviles de su risa. En primer lugar, lo invita a reconocer, valorar y criticar 
las consecuencias del predominio de las apariencias en su entorno y en sí mismo. En segundo lugar, el lector es llamado a llenar el lugar vacío de la escena, ¿cuáles son los signos distintivos de un hombre sabio? Por último, la estrategia de la negación ${ }^{16}$ rompe la expectativa del lector sobre la independencia del saber y lo llama a reconocer los vínculos entre poder y saber. La (aparente) derrota de Frutos Redondo revela, pues, de modo magistral cómo el saber se encuentra supeditado al ejercicio del poder en las sociedades burguesas decimonónicas. El "diccionario de Gobierno" (poder) se impone por ello al "diccionario de Autoridades" (saber). El poder produce saber. Esa es la verdad escandalosa cifrada en esta escena de humor de $L a$ Regenta.

La constatación del humor clariniano, por otro lado, le permite a Benito Pérez Galdós, en su prólogo a la edición de La Regenta de 1900, plantear que el "naturalismo" se origina en España, se vigoriza en Francia y vuelve a España en donde asume su signo distintivo: la armonía entre la seriedad y el humor:

En resumidas cuentas: Francia, con su poder incontrastable, nos imponía una reforma de nuestra propia obra, sin saber que era nuestra; aceptámosla nosotros restaurando el naturalismo y devolviéndole lo que le habían quitado, el humorismo, y empleando éste en las formas narrativa y descriptiva conforme a la tradición cervantesca $(1901: \mathrm{XI})^{17}$.

Pérez Galdós no advierte que en autores realistas como Leopoldo Alas el diálogo con la herencia literaria española, específicamente con El ingenioso hidalgo don Quijote de la Mancha, es más significativo que la influencia naturalista. El examen de la especificidad del realismo español decimonónico, la presencia del humor de raíz cervantina, ayuda a establecer las distancias correspondientes con el naturalismo literario francés. La lectura de La Regenta - pero también de Su único hijo- revela aún algo más que lo propuesto por el autor de Fortunata y Jacinta, a saber, que el nivel humorístico convive no sólo con el de lo serio, sino también con los otros niveles, incluso el de lo atroz. El humor en la escritura novelesca de Clarín enseña y hace estallar

${ }^{16}$ Mediante las negaciones, según Iser, se rompen "las expectativas suscitadas en el lector por alusiones al repertorio familiar" (1989a: 282).

${ }^{17}$ Pérez Galdós no advierte que todas las grandes obras novelescas, no sólo las españolas, tienden al humor. René Girard, en Mentira Romántica y verdad novelesca, escribe: "todas las obras novelescas tienden a la risa y la de Stendhal no es una excepción. Flaubert se supera en Bouvard y Pécuchet; Proust se realiza en el barón de Charlus; Stendhal se resume y culmina en las grandes escenas cómicas de Lamiel" (1963: 92). 
la ilusión de transparencia (el no-estilo) que cautiva a los escritores naturalistas. Cifra, asimismo, otro de los rasgos que hacen de Leopoldo Alas un gran escritor, pues en todos los grandes escritores, como lo piensa Gilles Deleuze en Conversaciones (1995: 172), el nivel humorístico es siempre fundamental.

\section{SOBRE LA INDETERMINACIÓN Y EL ROL ACTIVO DEL LECTOR}

El entramado textual de La Regenta no se encuentra absolutamente determinado por las ideas estéticas del naturalismo. Estas no logran contener la fuerza expresiva de un novelista que busca los medios más adecuados para construir sus ficciones. ¿La presencia de lugares vacíos en la novela de Alas no revela acaso la imposibilidad de su filiación a la serie naturalista, donde las novelas se caracterizan por un mayor control de la respuesta del lector? Los lugares vacíos del relato, que exigen una complementación cooperativa intensa e inagotable de parte del lector, permiten, por una parte, la puesta en diálogo de las perspectivas del narrador, los personajes, los acontecimientos y el lector ficticio ${ }^{18}$, y, por otra, hacen posible que la indeterminación se ponga al servicio de la significación. Cuando se advierte que "sólo el lector puede proporcionar un sentido estético-literario al objeto material de la obra escrita" (Acosta, 1989: 204), se propone que los lugares vacíos del texto activan la participación del lector. Los estudios teórico-críticos sobre el realismo y el naturalismo decimonónico señalan que los lugares vacíos del relato son inexistentes o escasos, lo que revelaría que estamos frente a una escritura que busca "mimar a cada instante, con cuidadosa vigilancia, los hábitos perceptivos del lector, sus presaberes, sus, en definitiva, competencias de las diversas series culturales" (Tarrio, 1979: 231). La diversidad de lecturas que gravitan en torno a obras realistas como La Regenta, no obstante, ayuda a leer de un modo distinto el problema. Permite plantear, por un lado, que los lugares vacíos en la novela de Alas son más abundantes y significativos de lo que hasta ahora se piensa y, por otro, que existe una distancia importante entre el realismo clariniano y las obras naturalistas que ejercen, sobre la base de la escasa presencia de lugares vacíos, un mayor control de la recepción. La estrategia de negación de las expectativas del lector, que lo estimula a participar en la producción del sentido a partir

${ }^{18}$ Sigo, en este punto, las proposiciones de Wolfgang Iser. Véase: El acto de leer. Madrid, Taurus, 1987. 
del cuestionamiento de un saber conocido, es también relevante en La Regenta. Dicha estrategia no sólo se activa en la escena de la apuesta, previamente comentada, entre Frutos Redondo y Pepe Ronzal, sino también en situaciones que involucran a otros personajes de la novela. Señalo sólo tres ejemplos más. Las acciones y deseos del Magistral impugnan el saber del lector sobre la incorruptibilidad de la iglesia Católica; el abismo insalvable que media entre los deseos de Ana Ozores y su situación conyugal obliga al lector a considerar que el matrimonio y el bienestar material no constituyen necesariamente fuentes de felicidad; el vicio que domina a Celedonio, quien a sus doce o trece años "daba una intención lúbrica y cínica a su mirada, como una meretriz de calleja" (Alas, 1900, I: 8), trastorna el saber del lector sobre la virtud e inocencia que suele acompañar las imágenes de infancia y pubertad.

¿Cuál es la estructura textual que determina la totalidad de la preorientación que la novela realista ofrece a sus potenciales lectores? Esta estructura textual es el lector implícito, es decir, "el esbozo del rol de lector en el texto" (Iser, 1987: 69). Esta construcción fictiva, teórica, inconclusa -como el texto del cual se origina-, en tanto se articula sobre la base de la serie de "realemas" de la narración, puede signarse como "realista". Por otro lado, el lector implícito, instancia en la cual se encadenan los sentidos sugeridos por el texto, determina la recepción. Éste, no obstante, se encuentra expuesto a sucesivas variaciones, pues, como destaca Rita Gnutzmann, es "una peculiaridad del texto a la vez que del lector real" (1991: 9). ¿Cómo la novela realista, entonces, logra constituirse en un dispositivo imaginario que incita, sugiere o suscita "algo" en el lector? El examen de la interacción del lector implícito y el lector real, expresada fundamentalmente en los lugares vacíos y en las negaciones del relato, contribuye a responder el interrogante.

La significación, así se ha sugerido, depende de la participación y cooperación del lector real. Si el lector real y el lector implícito coinciden, las expectativas de aquél han quedado satisfechas y, por lo mismo, se ha aceptado la visión de mundo del texto, que en la novela de Alas establece, en uno de sus niveles, que el deseo (que convierte a los hombres en modelos a imitar) es la fuente misma del mal que domina la sociedad vetustense. Por otro lado, la disensión indica que existen dificultades para aceptar la visión de mundo planteada en el texto. El bloque lector implícito-lector real no puede explicitarse, con todo, únicamente en términos de aceptación y rechazo, ya que puede cifrarse también en términos de sugestión, coerción, seducción, agitación, etc.

La novela es el discurso literario que se vincula de manera más intensa 
con la modernidad; por lo mismo, entra en relación polémica con el poder disciplinario de la sociedad normalizadora ${ }^{19}$. Es posible sostener, desde esta entrada, que la novela realista puede convertirse en una instancia de coerción y corrección de los individuos en la red social. Si el sistema de valores del texto, por ejemplo, es equivalente al que domina en la red social y el lector real coincide con el lector implícito, la novela funciona como un intensificador del poder. La complejidad del realismo literario, sin embargo, no puede reducirse a esta interesante lectura. La novela realista es un dispositivo imaginario que surge en un contexto disciplinario, por lo que no es extraño que afloren, por ejemplo, intuiciones sobre el funcionamiento del poder en los relatos que integran esta serie. Las más importantes novelas realistas parecieran develar las mentiras que se instalan en los diversos discursos que estabilizan el entramado social. La función más revulsiva de la palabra literaria, por lo mismo, se resuelve en la reacción a los juegos de verdad y las prácticas de poder, en la denuncia, en la resistencia $-y$ no en la aceptación- a los poderes hegemónicos ${ }^{20}$. Una lectura rigurosa de obras como Madame Bovary, Rojo y negro, Fortunata y Jacinta, Crimen y castigo y La Regenta hará visibles los signos negativos que imperan en la red social: el engaño, el interés, el fracaso, el fingimiento, el individualismo, el materialismo. ¿No residen acaso en esa visión crítica de la realidad social, de sus operaciones de poder y de sus posiciones de deseo, las lecturas más perturbadoras sugeridas por la novela de "Clarín"? ¿Y no se vinculan ellas a la posibilidad de fabulación utópica de un porvenir distinto cifrada en un personaje que la crítica literaria ha considerado marginal e intrascendente, Víctor Quintanar, quien descubre que "los hombres honrados y cristianos no matan tanto ni tan de prisa [como ocurre en las comedias de capa y espada de Calderón] (1990 II: 530)" (629) y percibe en el rostro desnudo de Álvaro Mesía no al adversario sino al prójimo, al hermano: la idea de Dios? ${ }^{21}$.

${ }^{19}$ Foucault, en Defender la sociedad (2000a), señala que una sociedad normalizadora comprende dos aspas interconectadas; un aspa actúa sobre el cuerpo de los sujetos, disciplinándolos, con la finalidad de convertirlos en individuos dóciles y útiles para el cumplimiento de las exigencias sociales; otra aspa actúa sobre la comunidad, regularizando la vida en sociedad. La anatomopolítica (disciplinaria) y el biopoder (regularizador) funcionan a partir de la norma y se constituyen en dos mecanismos, con los cuales la sociedad normalizadora ejerce un poder sobre los individuos, encauzando sus conductas. Puede consultarse, también, Vigilar y castigar (2000b).

${ }^{20}$ Albert Brent (1951) concibe La Regenta como novela de la reacción ante los signos de muerte que dominan en la red social, por lo que la singulariza como una escritura de la frustración. El incumplimiento de los proyectos de los personajes, por ejemplo, intensifica los sentimientos de derrota y pesimismo que dominan en la obra. Brent se explica lo anterior a partir de la biografía del autor, marcada por el fracaso en su vida sentimental.

${ }^{21}$ No amplificaré, por ahora, mis observaciones acerca del lector implícito de La Regenta. 
Una de las características de la escritura realista, según los trabajos dedicados a su estudio, es la escasa presencia de lugares vacíos. El control de la respuesta del lector y su limitada participación en la producción del sentido contribuirían a generar un discurso que plantea que la novela realista no posee "huecos" y que el lector realista es un lector pasivo o cautivo al cual se le ha privado de utilizar su imaginación. La doxa pareciera comenzar a gestarse en la virulenta crítica al realismo literario del Primer manifiesto surrealista y mantenerse hasta nuestros días, como lo demuestra un comentario de Andrés Zamora Juárez a La Regenta:

El carácter circunstanciado, inútilmente particularista de cada una de sus observaciones me induce a sospechar que tan sólo pretenden divertirse a mis expensas. No me permiten tener siquiera la menor duda acerca de los personajes: ¿será este personaje rubio o moreno? ¿Cómo se llamará? ¿Le conoceremos en verano...? Todas estas interrogantes quedan resueltas de una vez para siempre, a la buena de Dios; no me queda más libertad que la de cerrar el libro, de lo cual no suelo privarme tan pronto llego a la primera página de la obra, más o menos. ¡Y las descripciones! En cuanto a vaciedad, nada hay que se les pueda comparar; no son más que superposiciones de imágenes de catálogo, de las que el autor se sirve sin limitación alguna, y aprovecha la ocasión para poner bajo mi vista sus tarjetas postales, buscando que juntamente con él fije mi atención en los lugares comunes que me ofrece (Breton 1992: 21-22).

La omnisciencia que, según la poética de la época, al penetrar y conocer por completo al personaje lo engendra, lo hace de carne y hueso, también sirve para poseer y crear al lector al saturarlo de información, al irrumpir en él no dejándole ningún hueco en el que pueda ejercer su actividad creadora (Zamora 1999: 191).

La morosa caracterización de los personajes y la preocupación por la mención de detalles ajenos a la lógica argumental, según André Breton, provocan la expulsión de la libertad y la imaginación del acto de lectura. Zamora Juárez, por su parte, advierte que la omnisciencia del narrador crea y posee no sólo a los personajes sino también al lector, "no dejándole ningún hueco en el que pueda ejercer su actividad creadora". Breton y Zamora no advierten que la lectura de las obras cumbres del realismo literario exige la actividad creadora del lector. En La Regenta, por ejemplo, la tensión y el corte abrupto, que se expresan en la confesión diferida de Ana Ozores, producen un efecto de "suspense": verdadero lugar vacío que mueve al lector a la formulación de ciertas expectativas, las cuales podrán ser confirmadas o negadas; la inclusión de nuevos personajes es una estrategia fundamental mediante la cual el narrador introduce otras líneas de acción en el rela- 
to $y$, por lo mismo, nuevos interrogantes y expectativas; los comentarios del narrador, confiables o no confiables, inducen a reflexionar, cuestionar y criticar $^{22}$; los contrastes entre el mundo de la fantasía de Ana Ozores y el mundo de la realidad ficcionalizada inducen a defender o repudiar las acciones de la protagonista; la construcción de personajes en contrapunto, estudiada ampliamente por la crítica especializada, abre un vacío que invita al lector a reflexionar sobre el porqué del (aparente) abismo insondable que se interpone, por ejemplo, entre Camoirán y Fermín de Pas o entre Vetusta y Frígilis ${ }^{23}$. La significación está condicionada, según Iser, por el texto, "pero en una forma tal que permite que sea el lector mismo quien la produzca" $(1989 \mathrm{~b}: 147)^{24}$. La novela realista no es la excepción a esta imagen de la recepción estética de la obra literaria.

Una novela como La Regenta, dados los quiebres temporales que contiene, exige una máxima atención del lector. El estilo indirecto libre, heredado fundamentalmente de Flaubert, invita, asimismo, al lector a penetrar en la subjetividad de los personajes. Así lo entiende Mario Vargas Llosa, quien plantea que "el estilo indirecto libre significó el primer gran paso de la novela para narrar directamente el proceso mental, para descubrir la intimidad, no por sus manifestaciones exteriores (actos o palabras), a través de la interpretación de un narrador o un monólogo oral, sino representándola mediante una escritura que parecía domiciliar al lector en el centro de la subjetividad del personaje" (1975: 238-241). John Rutherford considera por ello que en La Regenta el estilo indirecto libre "intensifica el efecto de proyección del lector dentro de la mente de los personajes" (2002: 99). La fuerza aproximativa de la proyección, según Rutherford (1988), se vincula con la fuerza distanciadora de la ironía. El narrador, "inteligente y hábil", invita (mediante la ironía) al lector a una "relación de íntima y halagüeña complicidad $[\ldots]$ complicidad que excluye al público ingenuo, identificado

\footnotetext{
${ }^{22}$ María del Carmen Bobes Naves, en Teoría general de la novela. Semiología de "La Regenta" (1993), señala que el narrador no sólo se caracteriza por su capacidad épica (narrar una historia), sino que también por su capacidad dramática (preparar la materia narrativa: tensión, distancia, objetividad) y por su capacidad reflexiva (comentar lo que cuenta).

${ }^{23}$ Mariano Baquero Goyanes, en "Exaltación vital de La Regenta", escribe: "Alas enfrenta, pues, como tipos humanos polarmente opuestos a Camoirán y a De Pas, para así poder condenar la religiosidad científica, fría e inauténtica de éste, y exaltar la sentimental y ardiente del obispo, puesta de manifiesto, por ejemplo, en sus sermones [...] Tomás Crespo, Frígilis, es algo más que la contrafigura de otro personaje; lo es de toda la ciudad, de toda la sociedad ovetense" (1952: 208-211).

${ }^{24}$ Wolfgang Iser, en "La estructura apelativa de los textos" y "El papel del lector en Joseph Andrews y Tom Jones de Fielding" (1989), estudia cómo se generan los lugares indeterminados en las obras literarias. Véase Warning, Rainer (ed.). Estética de la recepción. Madrid, Visor, 1989.
} 
muchas veces con los personajes, que aquí quedan ridiculizados" (1988: 76). El comentador y traductor al inglés de La Regenta llama "intensidad" narrativa a la síntesis de rasgos estilísticos que hace de la novela de Clarín un texto complejo que exige un lector extraordinariamente competente:

Me asombró su intensidad: es una novela que exige que se lea con la atención y el cuidado continuos y totales que sólo prestamos a las ficciones breves, aunque está escrita con una elegancia que disimula esa intensidad. Por eso no fue comprendida en su época: La Regenta requiere lectores mucho más competentes que los contemporáneos de Clarín (Rutherford, 2002: 99).

La indeterminación se instala en la estructura de La Regenta y no sólo en la conclusión novelesca de Su único hijo, como lo ha indicado la crítica especializada ${ }^{25}$. Algo, sin embargo, no advierten los escritores y críticos que leen las obras realistas como relatos sin lugares vacíos que requieren un lector pasivo: la imposibilidad de sustraer dichas obras de un diálogo sólo limitado por nuestra magra inteligencia. Todos los libros, incluso aquellos que no han sido escritos todavía, se conectan y dialogan incesantemente en el texto infinito de la literatura. En ese texto infinito, que Jorge Luis Borges convirtió en una imagen ordenada -metáfora del universo- ${ }^{26}$, la novela de Alas espera nuevas "nupcias creadoras". Las aproximaciones críticas a las relaciones de La Regenta con obras de Flaubert, Zola, Eça de Queiroz, Pardo Bazán, Pérez Galdós, entre otros, cifra sólo un inicio interesante. ¿La participación en el diálogo de textos y conciencias no producirá nuevos lugares vacíos que inviten al lector a concretizar de un modo tal vez distinto la novela de Alas? ¿Cuántos vacíos residen aún en la zona de frontera en donde La Regenta y Su único hijo y La Regenta y Fortunata y Jacinta, por ejemplo, dialogan incesantemente? La Regenta no es una novela sin vacíos que anhele las bodas con un lector cautivo, pasivo o "femenino" (Zamora Juárez), porque ella es, en última instancia, una ficción literaria y el lenguaje de la literatura es el lenguaje de la indeterminación por excelencia.

Son exigencias básicas del (futuro) lector llamado a establecer una "cópula fértil” con La Regenta, novela abierta a la indeterminación en los ni-

${ }^{25}$ Zamora Juárez escribe: "al final de la siguiente novela de Clarín, Su único hijo, el lector se encontrará en una situación absolutamente inusitada dentro del realismo: la duda [...] A pesar de esta imagen del enrejado del confesionario en La Regenta, la novela es sólo el anuncio y el prólogo de esa nueva posibilidad textual" (1998: 232).

${ }^{26}$ Léase, en este sentido, el relato "La Biblioteca de Babel". 
veles estructural y dialógico, pues, la libertad, la actividad creativa y la capacidad crítica.

\section{REFERENCIAS}

Acosta, L. (1989). El lector y la obra. Madrid: Editorial Gredos.

Alas, Leopoldo, "Clarín" (1998). Sinfonía de dos novelas. Su único hijo. (Edición de Francisco Muñoz Marquina). Madrid: Ediciones Akal.

Alas, Leopoldo, "Clarín" (1900). La Regenta. (2 tomos). Madrid: Librería de Fernando Fé.

- (1998). Sinfonía de dos novelas. Su único hijo. (Edición de Francisco Muñoz Marquina). Madrid: Ediciones Akal.

Baquero Goyanes, M. (1952). "Exaltación de lo vital en La Regenta", en Archivum. Universidad de Oviedo. Tomo II, 5-21.

Bersani, L. (1975). "Le réalisme et la peur du désir”. Poétique, No 22, 177-195.

Beser, S. (1982). Clarín y "La Regenta". Barcelona: Ariel.

Bobes Naves, M. del C. (1993). Teoría general de la novela. Semiología de "La Regenta". Madrid: Editorial Gredos.

_ (2002). "Lectura feminista de La Regenta", en Coletes Blanco, Agustín (ed.), Clarín, visto en su centenario (1901-2001). Oviedo: Real Instituto de Estudios Asturianos.

Bonafoux, L. (1894). Huellas literarias. París: Garnier Hermanos, LibrerosEditores.

Brent, A. (1951). "Leopoldo Alas and 'La Regenta'. A study in Nineteenth Century Spanish Prose Fiction". The University of Missouri Studies, Vol. XXIV, No 2, Columbia, Missouri.

Breton, A. (1992). Manifiestos del surrealismo. Barcelona: Editorial Labor.

Clavería, C. (1942). "Flaubert y La Regenta de Clarín”. Hispanic Review, X, 116125.

Deleuze, G. (1995). Conversaciones. 1972-1990. Valencia: Pre-Textos.

Deleuze, G. y Guattari, F. (1990). Mil mesetas. Capitalismo y esquizofrenia. Valencia: Pre-Textos.

Even-Zohar, I. (1985). "Les regles dinsertion des réalèmes dans la narration". Littérature, No 57.

Fedorchek, R. (1978). “Clarín y Eça de Queiroz”. Nueva Revista de Filología Hispánica, XXVII, 141-151.

Foucault, M. (2000a). Defender la sociedad. Buenos Aires: Fondo de Cultura Económica de Argentina.

- (2000b). Vigilar y castigar. Madrid: Siglo Veintiuno de España Editores.

Galván, L. (1999). "Notas sobre la recepción de La Regenta: lector implícito y lecturas reales", en Rilce, № 15, V. 2, 401-412.

Genette, G. (2001). Umbrales. México D. F.: Siglo Veintiuno Editores. 
Gilman, S. (1975). "La novela como diálogo: La Regenta y Fortunata y Jacinta", en Nueva Revista de Filología Hispánica, Tomo XXIV, N² 2, 438-448.

Girard, R. (1963). Mentira romántica y verdad novelesca. Caracas: Universidad Central de Venezuela.

Gnutzmann, R. (1991). “Teoría y práctica acerca del lector implícito”. Revista de Literatura, No 105, 5-17.

Hamon, Ph. (1973). "Un discours contraint". Poétique, N 16.

Ingarden, R. (1989). “Concreción y reconstrucción”, en Warning, Rainer (ed.) Estética de la recepción. Madrid: Visor.

Iser, W. (1982). "La interacción texto-lector: algunos ejemplos hispánicos”. Revista Canadiense de Estudios Hispánicos, Vol. VI, No 2, 225-238.

- (1987). El acto de leer. Madrid: Taurus.

- (1989a). "La estructura apelativa de los textos", en Warning, Rainer (ed.). Estética de la recepción. Madrid: Visor.

(1989b). "El papel del lector en Joseph Andrews y Tom Jones de Fielding", en Warning, Rainer (ed.). Estética de la recepción. Madrid: Visor.

Kronik, J. (1987). "El beso del sapo: configuraciones grotescas en La Regenta", en Clarín y La Regenta en su tiempo: Actas del Simposio Internacional. Oviedo: Universidad de Oviedo, 517-524.

Laffitte, G. (1943). “Madame Bovary et La Regenta”. Bulletin Hispanique, XLV, 157-163.

Martínez Bonati, F. (2004). El Quijote y la poética de la novela. Santiago de Chile: Editorial Universitaria.

Melón Ruiz de Gordejuela, S. (1952). "Clarín y el bovarysmo", en Archivum. Universidad de Oviedo. Tomo II, pp. 69-87.

Naupert, C. (2001). La tematología comparatista entre teoría y práctica. La novela de adulterio en la segunda mitad del siglo XIX. Madrid: Arco libros.

Oleza, J. (1976). "Clarín: las contradicciones de un realismo límite”, en La novela del XIX: del parto a la crisis de una ideología. Valencia: Bello, 139-213.

Pardo Bazán, E. (1911). "La literatura francesa moderna. El naturalismo”, en Obras completas. Vol. 41. Madrid: Renacimiento.

Pérez Galdós, B. (1900). "Prólogo", en La Regenta (2 tomos). Madrid: Librería de Fernando Fé.

Rutherford, J. (1988). La Regenta y el lector cómplice. Murcia: Universidad de Navarra.

- (2002). "Mi Regenta, veinte años y un Quijote después”, en Coletes Blanco, Agustín (ed.). Clarín, visto en su centenario (1901-2001). Oviedo: Real Instituto de Estudios Asturianos.

Sobejano, G. (1991). Clarín en su obra ejemplar. Madrid: Editorial Castalia.

Tarrio, A. (1979). "Las competencias del lector realista". Senara, Nº 1.

Vargas Llosa, M. (1975). La orgía perpetua. Flaubert y Madame Bovary. Madrid: Taurus.

Villanueva, D. (2004). Teorías del realismo literario. Madrid: Editorial Biblioteca Nueva. 
Vodička, F. (1989). “La estética de la recepción de las obras literarias”, en Warning, Rainer (ed.) Estética de la recepción. Madrid: Visor.

Warning, R. (ed.) (1989). Estética de la recepción. Madrid: Visor.

Zamora Juárez, A. (1999). El doble silencio del Eunuco. Poéticas sexuales de la novela según Clarín. Madrid: Editorial Fundamentos. 